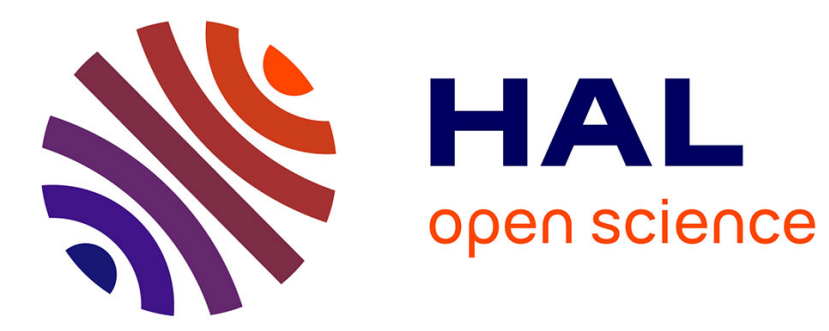

\title{
Thermal management of fully LTCC-packaged Cs vapour cell for MEMS atomic clock
}

R.K. Chutani, S. Galliou, N. Passilly, C. Gorecki, A. Sitomaniemi, M. Heikkinen, K. Kautio, A. Keranen, A. Jornod

\section{- To cite this version:}

R.K. Chutani, S. Galliou, N. Passilly, C. Gorecki, A. Sitomaniemi, et al.. Thermal management of fully LTCC-packaged Cs vapour cell for MEMS atomic clock. Sensors and Actuators A: Physical, 2012, 174, pp.58-68. 10.1016/j.sna.2011.11.025 . hal-00690693

\section{HAL Id: hal-00690693 https://hal.science/hal-00690693}

Submitted on 9 Apr 2021

HAL is a multi-disciplinary open access archive for the deposit and dissemination of scientific research documents, whether they are published or not. The documents may come from teaching and research institutions in France or abroad, or from public or private research centers.
L'archive ouverte pluridisciplinaire HAL, est destinée au dépôt et à la diffusion de documents scientifiques de niveau recherche, publiés ou non, émanant des établissements d'enseignement et de recherche français ou étrangers, des laboratoires publics ou privés. 


\title{
Thermal management of fully LTCC-packaged Cs vapour cell for MEMS atomic clock
}

\author{
R.K. Chutani ${ }^{\text {a }, *}$, S. Galliou ${ }^{a}$, N. Passilly ${ }^{a}$, C. Gorecki ${ }^{a}$, A. Sitomaniemi ${ }^{\text {b }}$, M. Heikkinen ${ }^{\text {b }}$, \\ K. Kautio ${ }^{\text {b }}$, A. Keränen ${ }^{\text {b }}$, A. Jornod ${ }^{c}$ \\ a Institut FEMTO-ST, CNRS (UMR 6174), Université de Franche Comté, ENSMM, 25044 Besançon, France \\ b VTT Technical Research Centre of Finland, P.O. Box 1100, 90571 Oulu, Finland \\ ${ }^{c}$ ASULAB, division of The Swatch Group Research and Development Ltd, 2074 Marin, Switzerland
}

\begin{abstract}
This paper describes a study of the thermal behaviour of fully packaged Caesium vapour cell developed in the framework of the European collaborative research project called "MEMS atomic clocks for timing, frequency control and communications (MAC-TFC)". This cell, along with various electronic and optical components, is embedded in a Low Temperature Co-fired Ceramics (LTCC) structure, in order to build a compact MEMS-based atomic clock. Functioning of such atomic clock depends on inner and outer environment of the Cs vapour cell, including parameters such as pressure and temperature of buffer gas. This paper is then devoted to study the thermal behaviour of a fully LTCC-packaged Cs vapour cell according to the ambient temperature change when it is locally temperature controlled. Simulations have been carried out by using analytical modelling and finite element based softwares. Different solutions concerning the LTCC structure such as bridges/suspensions, vacuum environment, metallic coating, as well as the optimal positions of the temperature-control elements have been investigated. Finally, preliminary experiments based on a prototype resulting from this study are presented and an additional solution based on the dynamic adjustment of the set temperature as a function of the ambient temperature is proposed.
\end{abstract}

\section{Introduction}

Atomic clocks are used as frequency references for a large number of applications. They provide enhanced accuracy and stability because their resonance frequency is determined by the energy transition of the atoms, and are consequently more stable than quartz-based clocks (especially at longer times). Nowadays, since more and more applications become mobile, the demand for small and low-power clocks is increasing. Thus, scientists focus their effort on the miniaturised version of the atomic clock, better known as chip scale atomic clock (CSAC) or MEMS atomic clock (MAC). MACs have consequently rapidly progressed since their first version proposed by Kitching et al. [1]. The European project "MEMS atomic clock for timing, frequency control and communications (MAC-TFC)" [2], aims to develop a miniaturised and low power atomic clock $(<150 \mathrm{~mW})$, presenting a fractional frequency deviation better than $6 \times 10^{-10} \tau^{-1 / 2}$ for an integration time $\tau$ shorter than one hour, and better than $1 \times 10^{-11} \tau^{-1 / 2}$ for longer time. Its

\footnotetext{
* Corresponding author at: Institut FEMTO-ST (UMR 6174), Département Micro Nano Sciences \& Systèmes, UFR Sciences et Techniques, Route de Gray, 25030 Besançon Cedex, France. Tel.: +33 381666162; fax: +33 381666423.

E-mail address: ravinder.chutani@femto-st.fr (R.K. Chutani)
}

central element is made of an Alkali vapour cell (a Caesium cell, Cs-cell) excited by a laser beam whose wavelength is locked on the Cs atomic hyperfine transition frequency which actually defines the reference frequency $v_{0}=9.192631770 \mathrm{GHz}$. The locking is achieved by coherent population trapping (CPT) spectroscopy [3]. The latter is particularly suitable because it does not require implementation of a microwave cavity since probing of the atomic resonance is directly realised by the laser beam thanks to a destructive quantum interference phenomenon. Consequently, it makes possible the further reduction in the size of cell and thus reduction of clock volume.

In the framework of MAC-TFC, alkali vapour micro-cells, made from MEMS fabrication techniques and based on compact cavities etched in a Si-wafer and sealed by anodic bonding with two borosilicate glass wafers, have been successfully fabricated [4-6]. Such vapour cells have dimensions: length $(6 \mathrm{~mm}) \times$ width $(4 \mathrm{~mm}) \times$ thickness $(2.4 \mathrm{~mm})$. Therefore, it has been chosen to embed the Cs-cell and the different components of the clock(VCSEL, detector, micro-optical components, etc.) in a Low Temperature Cofired Ceramics (LTCC) structure, which is highly suitable for hybrid 3D integration. LTCC is a well-established multi-layer technology, featuring the ability to integrate various elements (heaters, sensors, electronics, wires, shielding) in one module only, with high reliability, stability and alignment accuracy [7]. In the case of MACs, where 
magnetic and thermal environment have to be controlled, LTCC technology will allow to achieve a high level of miniaturisation with low processing costs.

This structure has then to be temperature controlled since VCSEL frequency and various properties of CPT resonances in Cs vapour cells are temperature dependent [8]. Indeed, because of the mean velocity of the Cs atoms (typically $230 \mathrm{~ms}^{-1}$ at $60^{\circ} \mathrm{C}$ ) in comparison with the cavity dimensions (order of magnitude: $1 \mathrm{~mm}$ ), the CPT line-width is easily broadened. Thus, the frequency stability of the clock cannot be achieved without the addition of a so-called buffer gas (usually $\mathrm{N}_{2}, \mathrm{He}, \mathrm{Ne}, \mathrm{Ar}$ ) $[9,10]$. The buffer gas is then required in order to prevent wall relaxation, to increase the atom-light interaction and to reduce the Doppler broadening. However, interactions between caesium atoms and buffer gas introduce a shift of the atomic hyperfine transition frequency. This phenomenon depends on the nature of the gas, pressure and temperature according to a two order polynomial law [3]. In general, the resulting thermal frequency sensitivity is too high and, thus, a mixture of two gases inducing opposite linear frequency-shifts is required (i.e. by means of a compensation method: Ar and Ne for example). Recently, in the framework of MAC-TFC, a quadratic temperature dependence of the Cs ground state hyperfine resonance frequency in a single Neon buffer gas has been observed [11]. The relatively low inversion temperature, around $80^{\circ} \mathrm{C}$, allows using one gas only and relaxes slightly the constraints onto the cell fabrication and, in particular, on the pressure control. Nevertheless, the thermal management remains a challenging part since the temperature of the cell must be maintained to within few hundreds of millikelvins at all times during operation, using as little power as possible, although the range of ambient temperature can be 0 to $55^{\circ} \mathrm{C}$. Then, a reasonable aim for the temperature sensitivity of the Cs-cell to the ambient temperature, once the temperature-control operates, is several millikelvins per Kelvin.

In this paper, a thermal management approach considering a LTCC-based structure is presented. Several solutions are investigated in order to achieve a low-power temperature control. The paper is organised as follows. In Section 2, we present the thermal management approach with respect to the power budget. Thermal simulations using the MEMS software tool Intellisuite and the FloTHERM computational fluid dynamics software are described in Section 3, and show that our solutions provide in steady-state a fine temperature distribution in the area of the cell. After preliminary experiments to estimate the power consumption, done with a prototype involving few of our propositions, a final approach based on the dynamic adjustment of the electronically driven set temperature as a function of the ambient temperature is proposed in Section 4.

\section{Thermal management approach}

\subsection{Problem and concept}

Basically, the MAC is made of several components that have to be temperature controlled. The Cs-cell, i.e., the heart of the clock, is surrounded by opto-electronic components (VCSEL and photodetector) to produce and detect the modulated optical beam, as well as optical components for shaping and polarizing the beam, and electronics to close the feedback loop of the modulating signal (Fig. 1). All these components are packaged in a LTCC structure.

The objective is then to maintain the inner temperature of the physics package constant whatever the external temperature is, within a determined range. The latter changes depending on the applications of the atomic clock and should be ideally as large as $\left[-40^{\circ} \mathrm{C}, 60^{\circ} \mathrm{C}\right]$ [12] or even $\left[-40^{\circ} \mathrm{C}, 70^{\circ} \mathrm{C}\right]$ [13]. The definition of this range is actually essential because it fixes the thermal management approach and the amount of required power. For a rough assessment, the inner target temperature (in K) can be written as:

$T_{\text {set }}=T_{\mathrm{amb}}+R \times\left(P_{\text {elec }}+P_{\mathrm{T} \text {-control }}\right)$

where $T_{\mathrm{amb}}$ is in Kelvins, $P_{\text {elec }}$ (in $\mathrm{W}$ ) is the power dissipated by the electronics (assumed to be a constant) located inside the volume to be temperature-controlled, $P_{\mathrm{T} \text {-control }}(\mathrm{in} \mathrm{W}$ ) is the controlled power $\left(0 \leq P_{\mathrm{T} \text {-control }} \leq P_{\mathrm{T} \text {-control Max }}\right)$ dissipated by the heaters in order to maintain the inner temperature of the volume at $T_{\text {set }}$ independently of the value of $T_{\mathrm{amb}}$. Finally, $R$ (in $\mathrm{KW}^{-1}$ ) denotes the overall thermal resistance of the system, from its heart at $T_{\text {set }}$ to its surrounding at $T_{\mathrm{amb}}$.

At first sight, it sounds reasonable to insulate as much as possible the physics package to reduce the power consumption. Indeed, when the ambient temperature is very low (for instance $T_{\mathrm{amb}}=-40^{\circ} \mathrm{C}$ ), the overall thermal resistance $R$ should be high in order to consume as little power as possible $\left(P_{\mathrm{T} \text {-control }}\right)$ and maintain an uniform temperature distribution inside the package. However, the waste heat generated by the embedded electronics cannot be ignored. Because of it $\left(P_{\text {elec }}\right)$, high overall thermal resistance, i.e., well insulated packages, can lead to overheating of the cell, if the ambient temperature is high. Thus, in this case, the overall thermal resistance $(R)$ should be low, since the maximum ambient temperature is defined by $T_{\text {set }}-R \times P_{\text {elec }}$. As a consequence, practically, such "ideal" ranges are difficult to achieve if one wants meanwhile to strongly reduce the power consumption. Indeed, for this purpose, it could be tempting to use a lot of waste heat coming from the embedded electronics (for lower ambient temperatures), but for high ambient temperatures, the waste heat has to be evacuated, thus $R$ cannot be very high. After preliminary studies, obtained at room temperature $[12,14]$ and in order to evaluate the solutions required to contain the power budget (among which utilisation of waste power), more complicated devices utilizing waste heat were developed. They include, e.g., variable thermal resistors made of an array of suspended thin gold beams electrostatically actuated [15], or thermal switches made of a bimetallic buckling disk [16] in order to change, actively or passively respectively, the thermal resistance as a function of the ambient temperature. Although these solutions could allow to reach a wide range of temperature such as $\left[-40^{\circ} \mathrm{C}, 50^{\circ} \mathrm{C}\right]$ with a limited power consumption (especially during transient regime), they strongly complicate the system and its fabrication, and are probably not yet highly reliable [15] or not yet miniaturised enough [16]. Consequently, for now, it seems more efficient to well insulate the physics package without benefiting from all the waste heat, as it can be seen in a recent and extensive thermal study of a CSAC, free of thermal switch, for which a range $\left[0^{\circ} \mathrm{C}, 50^{\circ} \mathrm{C}\right]$ was considered [17].

In addition to the range of ambient temperature, another important parameter is the target temperature $\left(T_{\text {set }}\right)$. Indeed, depending on the alkali atoms or the buffer gas mixture composition, operating temperatures can be $70^{\circ} \mathrm{C}[16,17], 75^{\circ} \mathrm{C}[14,15]$ or $80^{\circ} \mathrm{C}[12]$ and are always above the ambient temperature. Thereby, only warming, less power consuming than cooling, is required, so that, in steady state, the thermal flux always flows from inside (the warmest elements are the heaters) to outside, through the enclosure.

In the following study, we will consider a Cs (in Ar-only environment) cell set at a target temperature equal to $80^{\circ} \mathrm{C}$. This cell will be packaged in a LTCC structure so that the clock can be operated over the temperature range $\left[0,55^{\circ} \mathrm{C}\right]$ with power consumption lower than $150 \mathrm{~mW}$ in steady state. Several solutions will be examined in order to increase the thermal resistance of the system. It will be paid also attention to avoid overheating when the ambient temperature gets high. In addition, one aim will be to obtain a stable and uniform temperature inside the Cs vapour cell. It can be noted that depending on the application of such clock, the 

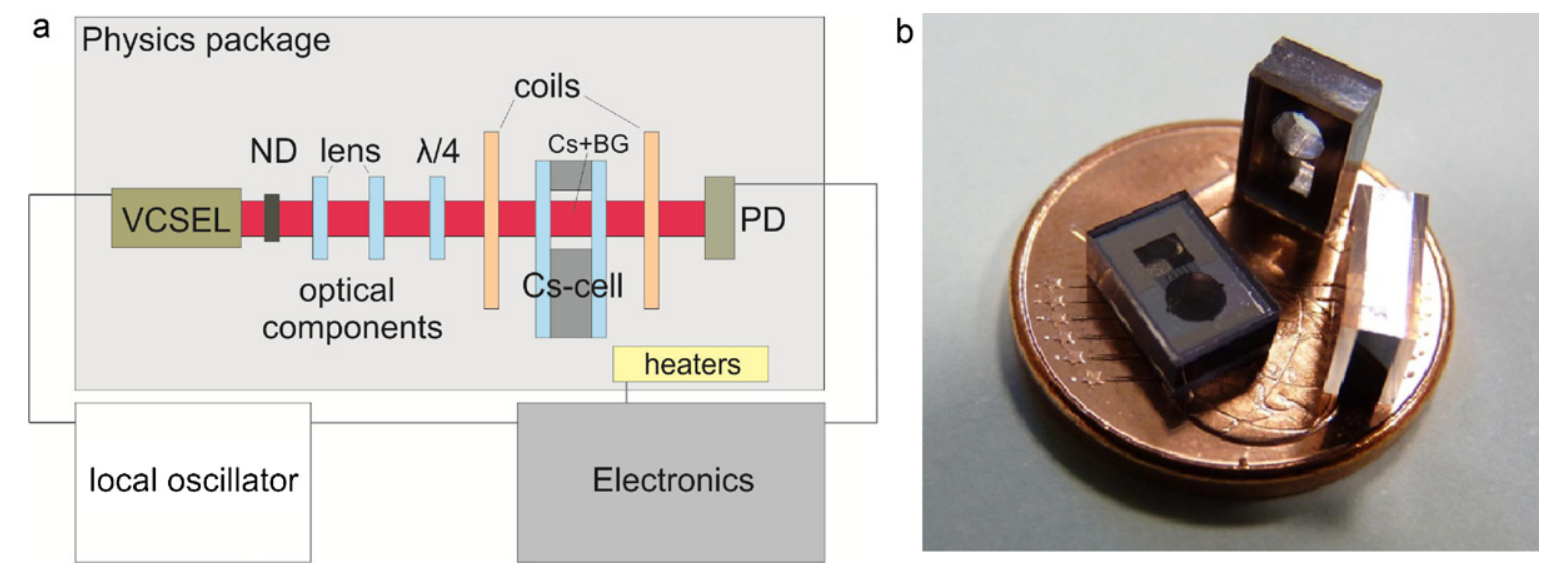

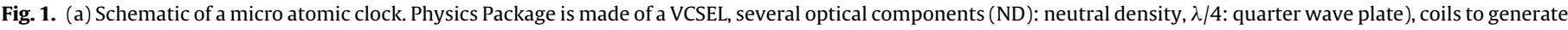

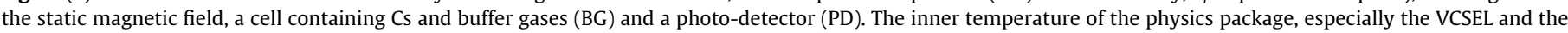
Cs-cell, has to be controlled. (b) Photograph of Cs-vapour cells.

temperature range could be extended (for outdoor applications such as, e.g., communication network synchronisation, seismic sensors network synchronisation, etc., or military applications), provided that an increase of the power consumption is acceptable.

In addition, the VCSEL has also to be temperature controlled. Nevertheless, because of its small volume (a $300 \mu \mathrm{m} \times 300 \mu \mathrm{m}$ chip, a few $10 \mu \mathrm{m}$ thick), heating can be done with a limited amount of energy. It can be noted that the VCSELs used in the framework of MAC-TFC [18] are made and optimised to work at high temperature and then, should not see their lifetime decrease for such operating temperatures. Consequently, in the following, we will focus mostly on the temperature control of the cell, although the same solutions will be applied to the VCSEL.

It has to be noted that the total electrical power, required to run the clock, is used by the electronics ( $4.6 \mathrm{Ghz}$ oscillator, modulator, synthesizer, control unit, RF oscillator, VCSEL power supply, etc.) and by the thermal management. Typically, one third of the total power budget can be attributed to maintain the physics package at a specific temperature, thus, requiring a careful optimisation of the thermal performances.

Hence, we choose first to simplify the addressed problem as follows: control the temperature of a quite big volume (the cell) by means of a very small temperature sensor (typically a resistive transducer like a thermistor, a deposited resistor, or a diode-based sensor) (Fig. 2).

In this framework, a servo-control is able to lock the sensor temperature at the set temperature, by managing the power dissipated by the heaters. The ideal situation requires then, firstly, a small section of the conductive path at the sensor location so that the section temperature is the same as the sensor temperature, and, secondly, negligible thermal exchanges between the inner volume and the enclosure $\left(\Phi_{12} \approx 0\right)$. Such situation would lead to a uniform temperature distribution inside the volume to be temperature controlled. It can be mentioned, referring to Eq. (1), that $R$ denotes the equivalent thermal resistance of both the conductive path and the "parasitic" path. In the following, two points have to be discussed to get an isothermal volume at the desired temperature: the conductive thermal path where the thermal flux can be controlled must be calibrated $\left(\Phi_{\mathrm{c}}\right.$ symbolises conductive exchanges through solid supports), and the parasitic exchanges (flux $\Phi_{12}$ ) all over the surfaces must be minimised (i.e. must be negligible in comparison with the controlled conductive flux).

In addition to the exchanges through solid support $\left(\Phi_{\mathrm{c}}\right)$, i.e. made by "bulk" conduction, the exchanges between the volume to be controlled and the enclosure can have different origins. Indeed, the non-controlled flux $\left(\Phi_{12}\right)$ can be attributed to gas conduction and convection, or to radiation between the two surfaces $S_{1}$ and $S_{2}$. Let us, in the following, evaluate the relative importance of each way of heat transfer involved.

\subsection{Analytical approach}

Gaseous conduction and convection depends on the volume and the pressure inside the enclosure. Free convection of the air inside the enclosure can be examined according to the Rayleigh number $R_{\mathrm{a}}$. In our case, the general characteristic length $L$ (i.e. size of the gap between the temperature controlled volume and the enclosure) would be typically about 1 or $2 \mathrm{~mm}$. For this value, $R_{\mathrm{a}}$ is much smaller than the critical value for which convection takes place, even at atmospheric pressure $p=10^{5} \mathrm{~Pa}$.

Although convection does not exist in our case, heat conduction by air has to be considered. It can be sorted in four regimes according to the Knudsen number $K_{\mathrm{n}}=l_{\mathrm{mfp}} / L$, where $l_{\mathrm{mfp}}$ is the molecular mean free path inversely proportional to the pressure $p$. Then, in secondary vacuum, i.e., for $p<1 \mathrm{~Pa}$ and $K_{\mathrm{n}}>10$, the relevant regime is the so-called free-molecule regime; for $1 \mathrm{~Pa}<p<10^{2} \mathrm{~Pa}$ and $10^{-1}<K_{\mathrm{n}}<10$, it is the transition regime; for $10^{2} \mathrm{~Pa}<p<10^{3} \mathrm{~Pa}$ and $10^{-2}<K_{\mathrm{n}}<10^{-1}$ the slip-flow regime (or temperature jump),

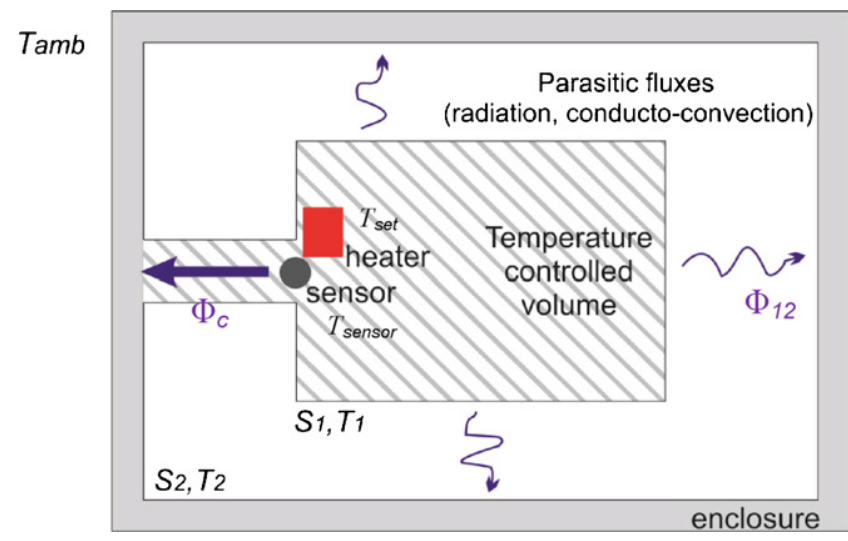

Fig. 2. Sketch of exchanges; In case of vacuum inside the enclosure, radiation exchanges $\Phi_{12}$ exists. Otherwise, $\Phi_{12}$ is due to conduction by the air inside enclosure, and convection. $\Phi_{\mathrm{c}}$ symbolises conductive exchanges through solid supports between the cell and the enclosure. Ideally, if the parasitic flux $\Phi_{12}$ is negligible in comparison with $\Phi_{\mathrm{c}} \approx P_{\mathrm{T} \text {-control }}$, and when the main flux $\Phi_{\mathrm{c}}$ is concentrated into a controlled path, the volume can then be temperature-controlled and is rather isothermal at $T_{1} \approx T_{\text {sensor }}=T_{\text {set }}$ (without power source other than that of the heater) 
and finally, $p>10^{3} \mathrm{~Pa}, K_{\mathrm{n}}<10^{-2}$ corresponds to the continuum regime.

The academic model of conduction through a gas layer between two parallel plates at temperatures $T_{1}$ and $T_{2}$ is usable and rather close to the actual concerned situation (see Fig. 4(c) and Fig. 6). In the free molecule regime, the thermal flux per unit of area (in $\mathrm{W} \mathrm{m}^{-2}$ ) between the plates can be written [19-21]:

$\varphi_{\mathrm{FM}}=-\left(\frac{8 k_{\mathrm{B}}}{\pi m}\right)^{1 / 2}\left(\frac{\alpha_{1} \alpha_{2}}{\alpha_{1}+\alpha_{2}-\alpha_{1} \alpha_{2}}\right)\left(1+\frac{\xi}{4}\right)\left(T_{1}^{1 / 2}-T_{2}^{1 / 2}\right) p$

where $k_{\mathrm{B}}$ is the Boltzmann constant, $m$ the molecular mass, $\xi$ the number of internal degrees of freedom, and $\alpha_{1}$ and $\alpha_{2}$ the accommodation coefficients of the hot plate at $T_{1}$ (close to $T_{\text {set }}$ ) and the cold plate at $T_{2}$ (close to $T_{\mathrm{amb}}$ ), respectively.

In the continuum regime the heat flux $\left(\right.$ in $\mathrm{W} \mathrm{m}^{-2}$ ) is given by the well-known Fourier heat conduction law:

$\varphi_{\mathrm{C}}=\frac{k(T)}{L}\left(T_{1}-T_{2}\right)$

where $k(T)$ is the gas thermal conductivity which depends on temperature $T$. It can also be described by means of the dynamic viscosity of air, its heat capacity at constant volume, and the ratio between the heat capacity at constant pressure and the one at constant volume.

Between both previous regimes, Sherman proposed the following interpolation for a practical calculation of the transition regime [22]:

$$
\varphi_{\mathrm{TR}}=\frac{1}{1+\varphi_{\mathrm{FM}} / \varphi_{\mathrm{C}}} \cdot \varphi_{\mathrm{C}}
$$

This model of two parallel plates is relevant for the heat exchanges between each surface of the warm Cs-cell at $T_{\text {set }}\left(S_{1}\right.$ or one part of $S_{1}$ at $T_{1}=T_{\text {set }}$ in Fig. 2) and the facing surface at the ambient temperature (surface $S_{2}$ at uniform temperature $T_{2}=T_{\mathrm{amb}}$ ).

In the case of conduction through the air, the thermal flow (in W) outgoing from $S_{1}$ can be expressed as:

$\Phi_{12 \_\mathrm{c}}=S_{1} \times \varphi_{12 \_\mathrm{c}}=S_{1} \times h \times\left(T_{\mathrm{set}}-T_{\mathrm{amb}}\right)$

where $h$ is an exchange coefficient (in $\mathrm{Wm}^{-2} \mathrm{~K}^{-1}$ ), and $\varphi_{12 \_c}$ is given by one of the Eqs. (2), depending on the gas pressure.

Obviously, radiation exchanges have also to be taken into account. Let us consider the simple case of two surfaces $S_{1}$ and $S_{2}$ with exchanges only between them. In addition, both surfaces are assumed to be isothermal, at $T_{1}$ and $T_{2}$, respectively, opaque, diffuse and grey (with emissivity's $\varepsilon_{1}$ and $\varepsilon_{2}$ respectively), and characterised by uniform radiosity and irradiation. Note that with these assumptions, the emissivity of a surface is equal to its absorption coefficient. Then, the resulting net flux is (see [23] for example, $\sigma$ being the Stefan constant):

$$
\begin{aligned}
\Phi_{12 \_r} & =S_{1} \times \varphi_{12 \_r} \\
& =S_{1} \times \frac{\sigma T_{1}^{4}-\sigma T_{2}^{4}}{\left(1-\varepsilon_{1} / \varepsilon_{1}\right)+\left(1 / f_{12}\right)+\left(S_{1} / S_{2}\right)\left(1-\varepsilon_{2} / \varepsilon_{2}\right)}
\end{aligned}
$$

$f_{12}$ being the associated view factor.

Based on Eqs. (3) and (4), air conduction and radiation between both surfaces are compared in Fig. 3, as a function of the air pressure. It is clear that the air conduction can be almost suppressed by a pressure reduction until the secondary vacuum $\left(p<10^{-1} \mathrm{~Pa}\right)$. In this case, radiation becomes the dominant heat transfer process and, a special attention should be paid to the emissivity coefficients of the surfaces.

One way to reduce them is to deposit low-emissive coatings over the exchanging surfaces. As mentioned previously, the cell is

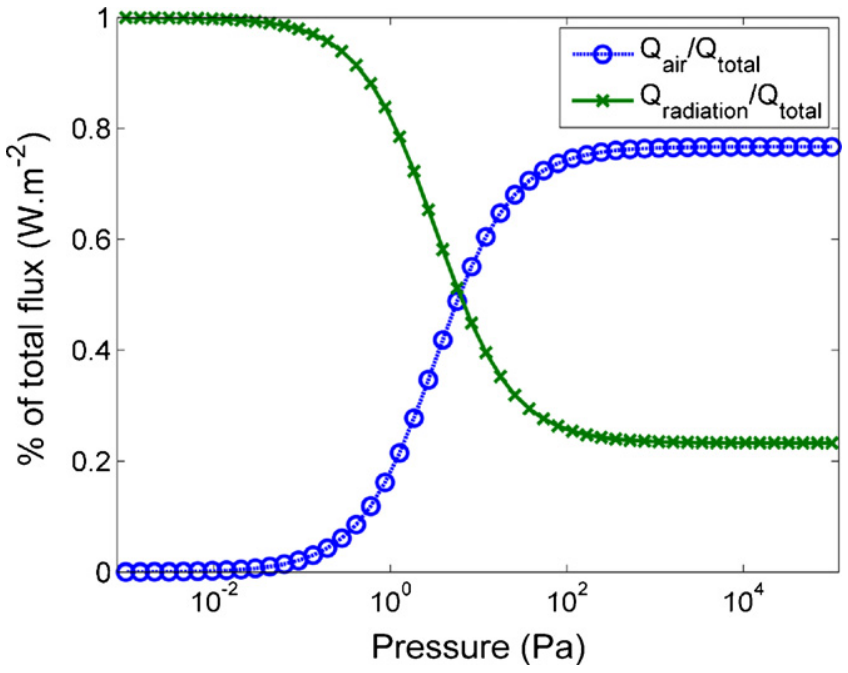

Fig. 3. Relative importance of air conduction and radiation between two surfaces, versus pressure, according to Eqs. (2)-(4). For these calculations, the accommodation coefficients of both surfaces are equal to 0.8 , emissivities are equal to 0.9 , the view factor is $f_{12}=0.9$, and the ratio $S_{1} / S_{2}$ is 0.1 .

made of a glass-silicon sandwich, sealed by anodic bonding. The silicon is a rather good conductor $\left(\lambda_{\mathrm{Si}} \approx 140 \mathrm{~W} \mathrm{~m}^{-1} \mathrm{~K}^{-1}\right)$ but also an emissive material $\left(\varepsilon_{\mathrm{Si}}=0.5[24,25]\right)$, and glass is particularly emis$\operatorname{sive}\left(\varepsilon_{\text {Glass }}=0.9[26]\right)$ and a poor conductor $\left(\lambda_{\text {Glass }} \approx 1.2 \mathrm{~W} \mathrm{~m}^{-1} \mathrm{~K}^{-1}\right)$. Once packaged, the cell has its surfaces facing LTCC ones made of ceramics, whose emissivity and conductivity are respectively $\varepsilon_{\text {LTCC }}=0.9$ [27] and $\lambda_{\text {Ceramics }} \approx 2.8 \mathrm{~W} \mathrm{~m}^{-1} \mathrm{~K}^{-1}$. Emissivities can then be easily lowered by a metallic coating onto the surfaces: aluminium emissivity is for instance equal to 0.05 [28], silver and gold ones are even lower. Consequently, coating all the surfaces of the cell and of the surrounding LTCC could, according to the Eq. (4), reduce the amount of radiations by a factor 20 . In addition to the vacuum environment, this solution is important to minimise the thermal budget, and especially to reduce temperature gradients inside the cell. Indeed, the larger the radiation exchanges are, the larger the inner temperature gradients. It has to be noticed that magnetic materials - used for soldering/bonding pads or coatings - are prohibited because of the high sensitivity of atoms to the magnetic field, which can affect the CPT process.

\subsection{Selected topology}

From the simple approach described above, parasitic fluxes $\Phi_{12}$ can then have different origins such as conduction/convection of air and radiation of surfaces. On the one hand, convection is negligible due to the small gap between the volume to be temperature controlled and the enclosure and, on the other hand, solutions such as, second-vacuum packaging (typically $10^{-1} \mathrm{~Pa}$ ) and proper metallic coatings on surfaces, should allow decreasing air conduction and surface radiation respectively. Therefore, we should now consider the problem of embedded electronics, and the thermal fluxes by bulk conduction that should be minimised and canalised in order to be controlled. It requires a more accurate description of the physics package architecture as it is done in Fig. 4.

Regarding the solid conduction, the principle of "bridges" as high thermal resistance links between the area to be temperaturecontrolled and parts submitted to ambient temperature changes has been selected. They allow the creation of an "island" on which the cell is hanged (Fig. 4a). It has to be noted that the same structure, although a bit smaller, is made to suspend the VCSEL (Fig. 4b). These "bridges", similar to the one made of Cirlex in [17], are made of LTCC, i.e., a rather insulating material $\left(\approx 2.8 \mathrm{~W} \mathrm{~m}^{-1} \mathrm{~K}^{-1}\right)$, and their 
a

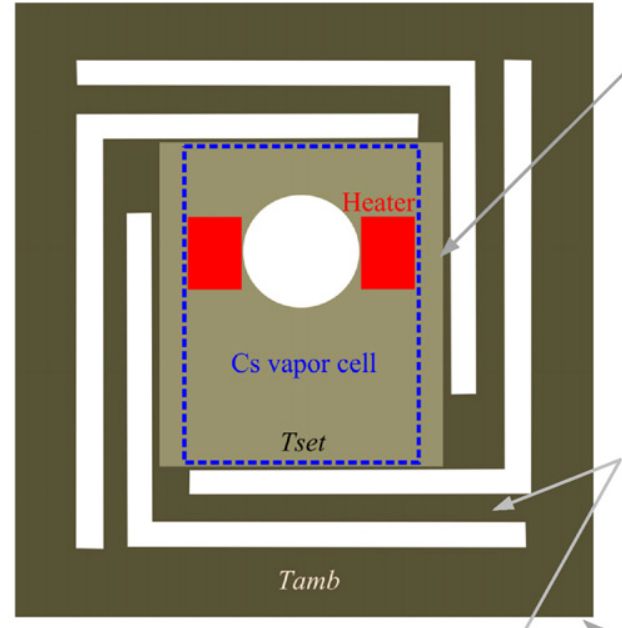

b

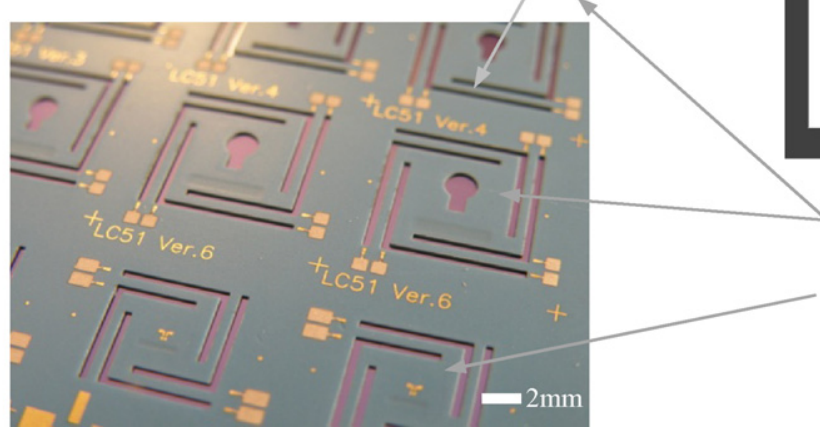

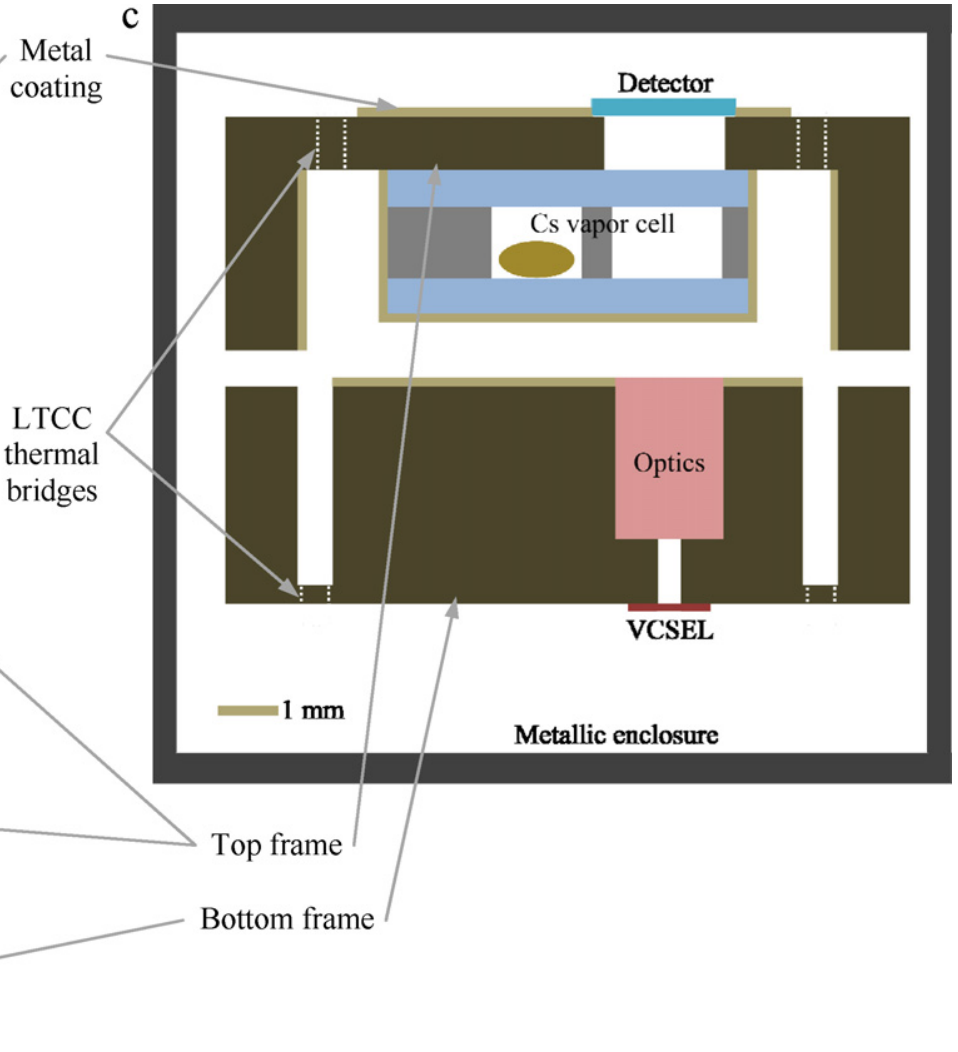

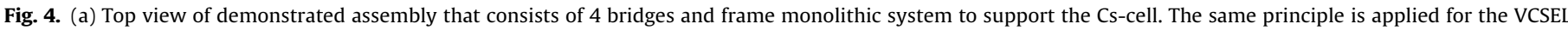

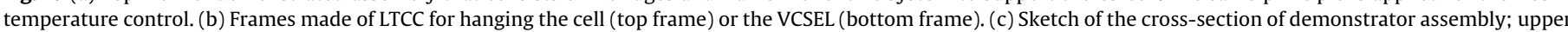
part is cell sub-system and lower part is VCSEL sub-system. All these components are packaged in a multi-layers LTCC structure and encapsulated under vacuum.

dimensions can be easily calibrated. A resistance of $17^{\circ} \mathrm{C} / \mathrm{mW}$ per bridge can then be achieved (bridges are about $0.5 \mathrm{~mm}$ width, $6 \mathrm{~mm}$ long, resistance calculation does not include the electrical leads). In addition, only one temperature sensor is needed to control the area temperature, since symmetries operate. This sensor, along with the heaters, is buried into the multi-layers LTCC material.

From the data and guidelines discussed above, various topologies have been examined, e.g., a unique temperature-controlled insulated area supporting all the components (including some of the dissipative electronics) such as in $[15,16]$, or a unique temperature-controlled insulated area incorporating the cell, VCSEL and the optics such as in [14,17] or only the cell [29]. Finally, our selected solution (see Fig. 4c) consists of two insulated islands:

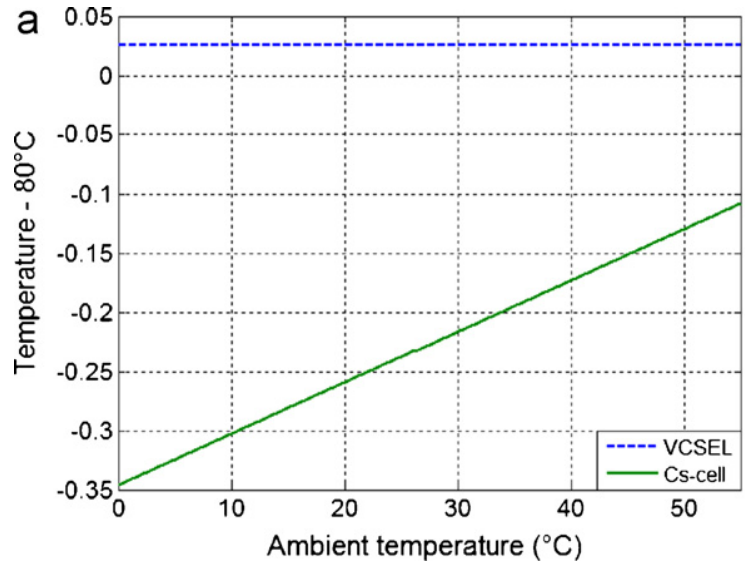

one including the Cs-cell and the photodiode, and one corresponding to the VCSEL. Each block is separately temperature-controlled at its own set temperature. The optics sub-system (including neutral density, two lenses and a quarter-wave plate) is itself separated from the VCSEL island. Thus, the suspensions support only the VCSEL or the cell. The power dissipated by the integrated electronics located near the VCSEL (about $15 \mathrm{~mW}$ ), is directly evacuated to the outside by conduction and does not heat the elements to be temperature-controlled. The enclosure surrounding the two LTCC packages is under vacuum.

In order to discriminate roughly the different topologies, simple calculations based on the electrical analogy have been performed This approach allows to easily consider the temperature-control

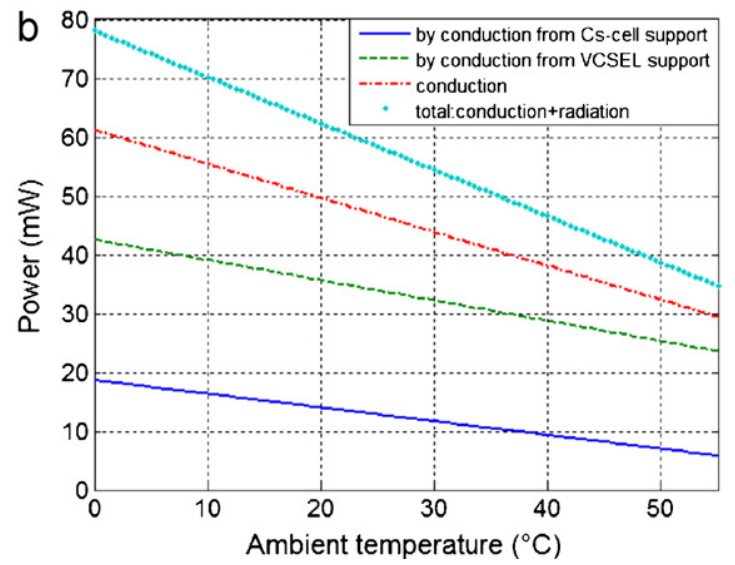

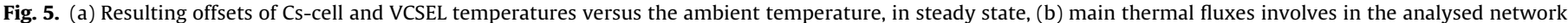

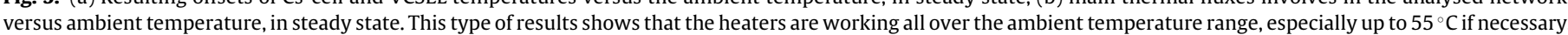



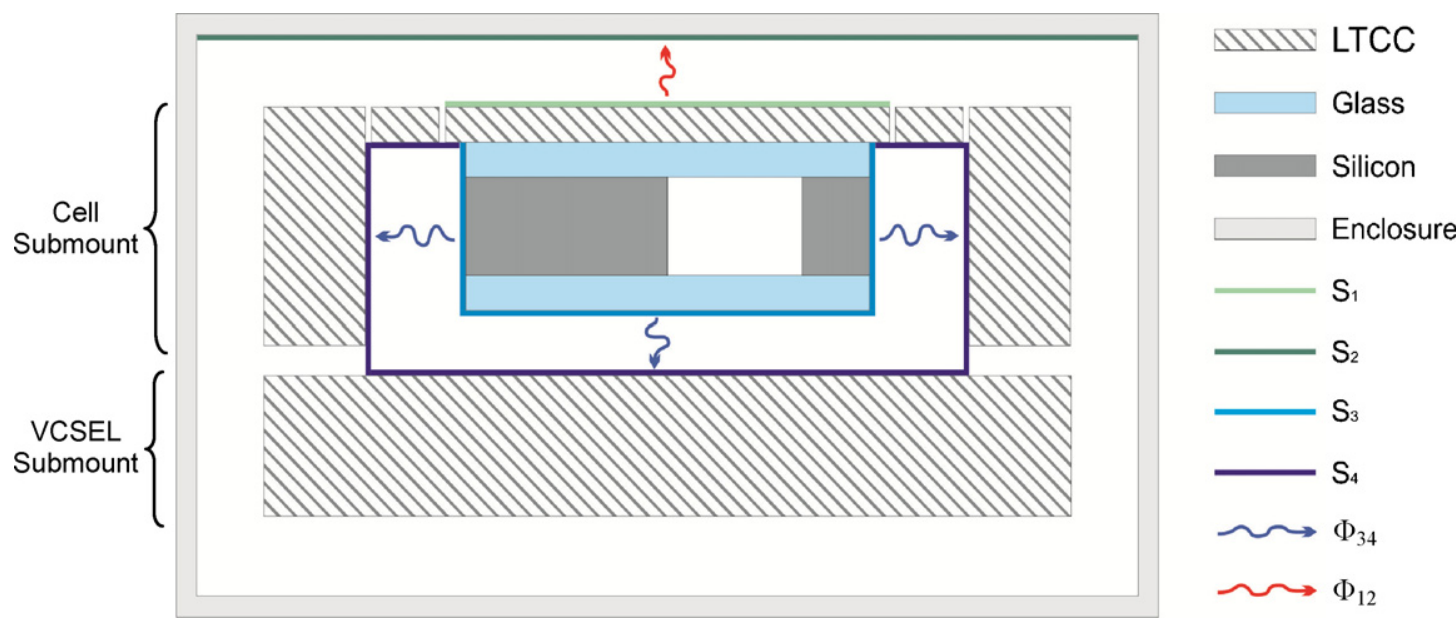

Fig. 6. Radiation exchanges between various faces of packaged Cs-cell

feedback loops and a trade-off between the insulation and the power distribution can be found. An example of resulting data is given in Fig. 5.

Such approach can also allow the rough estimation of the transient behaviour of the mean temperature of the Cs-cell. For instance, at room temperature, and if the available heating power is limited to $100 \mathrm{~mW}$, less than a minute would be required to warm-up the Cs-cell at an operating temperature of $80^{\circ} \mathrm{C}$.

\section{Analysis of the selected architecture by finite element method (FEM)}

Finite elements simulations were made both with the MEMS dedicated software Intellisuite and with the CFD (Computational Fluid Dynamics) software FloTHERM. The latter has been used to simulate the overall assembly, whereas a focus on the more sensitive part (i.e. the Cs-cell with its LTCC support) has been performed by means of Intellisuite. It allowed to investigate the temperature distribution and variation inside the cell, especially inside the silicon, with respect to change of external ambient temperature. As complete MAC package is kept under vacuum $\left(10^{-3}\right.$ mbar in our case), as seen previously, heat loss at this pressure by convection/conduction through air is negligible and thus, heat exchanges by means of radiations are considered to be predominant.

\subsection{Radiation and boundary conditions}

According to Fig. 6, heat exchanges through radiation should be examined for two different areas: The first one (case no 1) concerns the exchanges between the cell surfaces and its facing ones made of LTCC, surrounding it similarly to a closed box, whereas the second one (case no 2), includes exchanges between the LTCC cell support and the metallic enclosure.

For the 1st case, five sides of the cell are considered for exchanges with the facing LTCC surfaces. Since the cell is based on a glass-silicon sandwich, side's surfaces can be either only glass (bottom side) or include three "layers" made of silicon and glass.

Theoretically, the net radiation flux $\varphi_{\mathrm{j}}^{\mathrm{R}}$ from one of these surfaces $j$ is the difference between the leaving $\operatorname{part} \varphi_{\mathrm{j}}^{\mathrm{l}}$ and the incident one $\varphi_{\mathrm{j}}^{\mathrm{i}}$ :

$\varphi_{\mathrm{j}}^{\mathrm{R}}=\varphi_{\mathrm{j}}^{\mathrm{l}}-\varphi_{\mathrm{j}}^{\mathrm{i}}$

Based on the same assumptions as for Eq. (4) (opaque grey surfaces, isotropy, etc.), the leaving flux $\varphi_{\mathrm{j}}^{\mathrm{l}}$ can be described as the sum of the emitted flux according to the Stefan-Boltzmann law, i.e., $\varepsilon_{\mathrm{j}} \sigma T_{\mathrm{j}}^{4}$, and the reflective part of the incident flux, equal to $\left(1-\varepsilon_{\mathrm{j}}\right) \varphi_{\mathrm{j}}^{\mathrm{i}}$, since the absorption coefficient is equal to the emissivity:

$\varphi_{\mathrm{j}}^{\mathrm{l}}=\varepsilon_{\mathrm{j}} \sigma T_{\mathrm{j}}^{4}+\left(1-\varepsilon_{\mathrm{j}}\right) \varphi_{\mathrm{j}}^{\mathrm{i}}$

Moreover, inside an enclosure, the incident flux $\varphi_{\mathrm{j}}^{\mathrm{i}}$ is the sum of the fluxes coming from all the $n$ surfaces of the enclosure, seen by the surface $j$, i.e.:

$\varphi_{\mathrm{j}}^{\mathrm{i}}=\sum_{k=1}^{n} f_{\mathrm{jk}} \varphi_{\mathrm{k}}^{\mathrm{l}}$

Where the view factor $f_{\mathrm{jk}}$ is the fraction of the thermal flux leaving the surface $j$ that reaches the surface $k[30,31]$.

Thus, it is possible to write each net radiation flux $\varphi_{\mathrm{j}}^{\mathrm{R}}(1 \leq j \leq n)$ versus the $n$ surface temperatures $T_{\mathrm{j}}$ (working as $T_{\mathrm{j}}^{4}$ ) from Eqs. (5-a) $-(5-c)$, involving the $n$ emissivities and the $n \times n$ view-factors.

Although relationships exist between the view-factors, the system is difficult to solve analytically when more than three surfaces are considered. Then, it is relevant to use ComputerAided-Design software, provided that it can take into account the complete radiation problem: this is actually more effective with FloTHERM, than with Intellisuite. However, Intellisuite is userfriendly and has been consequently employed to get a preliminary assessment. Basically, Intellisuite is able to simulate exchanges at boundaries thanks to an exchange coefficient $h$ as described by Eq. (3). This method, although convenient for conduction or convection exchanges, requires few approximations to consider radiationbased exchanges. For instance, surfaces have been gathered in order to limit to two the number of surfaces involved in a system and expressions such as $\left(T_{\mathrm{i}}^{4}-T_{\mathrm{j}}^{4}\right)$ have been derived into $4 T_{\mathrm{i}}^{3}\left(T_{\mathrm{i}}-T_{\mathrm{j}}\right)$, i.e. an expression compatible with a conduction or convection-type law, since the maximum temperature difference never exceeds $100{ }^{\circ} \mathrm{C}$ inside the device. Then, for the case no 1 mentioned above, all the cell-surfaces are gathered into one having a mean emissivity equal to the weighted emissivities of silicon and glass according to their relative surfaces. This cell-surface exchanges only with one surrounding surface in LTCC, as described by Eq. (4) where an appropriate view factor $f_{12}$ is set [30]. Thanks to the previous assumptions, Eq. (4) is then transformed in the form of Eq. (3), which exhibits an exchange coefficient $h$. Similarly, in case no 2 , the rectangular LTCC island supporting the cell is assumed to exchange only with its facing enclosure surface. 
Table 1

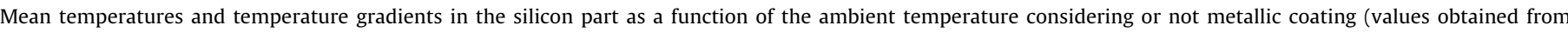
Intellisuite).

\begin{tabular}{|c|c|c|c|c|c|c|c|c|c|}
\hline \multirow[b]{2}{*}{$T_{\mathrm{amb}}\left({ }^{\circ} \mathrm{C}\right)$} & \multicolumn{3}{|c|}{ No metal coatings } & \multicolumn{3}{|c|}{ Metal coating onto LTCC } & \multicolumn{3}{|c|}{ Metal coating on both LTCC and cell } \\
\hline & $T_{\text {set }}\left({ }^{\circ} \mathrm{C}\right)$ & $\begin{array}{l}\text { Mean } T_{S i} \\
\left({ }^{\circ} \mathrm{C}\right)\end{array}$ & $\begin{array}{l}\text { Temperature gradient } \\
\text { in silicon }\left({ }^{\circ} \mathrm{C}\right)\end{array}$ & $T_{\text {set }}\left({ }^{\circ} \mathrm{C}\right)$ & $\begin{array}{l}\text { Mean } T_{\mathrm{Si}} \\
\left({ }^{\circ} \mathrm{C}\right)\end{array}$ & $\begin{array}{l}\text { Temperature gradient } \\
\text { in silicon }\left({ }^{\circ} \mathrm{C}\right)\end{array}$ & $T_{\text {set }}\left({ }^{\circ} \mathrm{C}\right)$ & $\begin{array}{l}\text { Mean } T_{\mathrm{Si}} \\
\left({ }^{\circ} \mathrm{C}\right)\end{array}$ & $\begin{array}{l}\text { Temperature gradient } \\
\text { in silicon }\left({ }^{\circ} \mathrm{C}\right)\end{array}$ \\
\hline 25 & 83.32 & 80.00 & 0.075 & 81.64 & 80.00 & 0.040 & 81.10 & 80.00 & 0.030 \\
\hline 0 & & 78.92 & 0.100 & & 79.46 & 0.056 & & 79.61 & 0.041 \\
\hline 55 & & 81.53 & 0.040 & & 80.88 & 0.020 & & 80.62 & 0.014 \\
\hline
\end{tabular}

\subsection{Applied power}

The system temperature is measured by a sensor $\left(T_{\text {sensor }}\right)$ embedded in the LTCC suspension and heaters are powercontrolled through a feedback loop system amplifying the temperature difference between the sensor temperature and the set temperature $\left(T_{\text {set }} \approx 80^{\circ} \mathrm{C}\right.$ in our case). The feedback loop (limited to a proportional action of gain $G$ ), controlling the dissipated power over a surface area $S$ is then described by (the heating flux $\varphi_{\mathrm{h}}$ goes from outside the heater towards the area to heat):

$\varphi_{\mathrm{h}} \times S=-G\left(T_{\text {sensor }}-T_{\text {set }}\right)$

In Intellisuit, an exchange coefficient $h$ can then simply be identified as:

$\varphi_{\mathrm{s}}=-\varphi_{\mathrm{h}}=h \times\left(T_{\text {surf }}-T_{\text {env }}\right)$

where $h=G / S, \varphi_{\mathrm{s}}$ being the thermal flux going out from the surface, $T_{\text {surf }}$ the surface temperature equal to that of an ideal sensor located at the temperature-controlled surface, and $T_{\text {env }}$ the temperature of the imaginary environment. With such assumption, the controlled-power looks like a classical convection-type exchange usable in Intellisuite, and if $G$ is sufficiently high, the heater surface temperature $T_{\text {surf }}$ (i.e. $T_{\text {sensor }}$ ) tends to $T_{\text {env }}$ which is set at $T_{\text {set }}$.

\subsection{Simulations results}

After testing different positions of heaters (and sensor), simulations with Intellisuite have been performed for three different cases; i.e. no metallic coatings, metallic coatings onto the LTCC part, and metallic coatings on both LTCC and the cell surfaces. Each case has been studied at three different ambient temperatures, i.e., $0^{\circ} \mathrm{C}$, $25^{\circ} \mathrm{C}$ and $55^{\circ} \mathrm{C}$ in order to get the temperature sensitivity of silicon with respect to change in ambient temperature. Various simulation results are shown in Fig. 7 for one interesting topology, and summed-up in Table 1.

It is clear that metallic coatings, by reduction of surface emissivities, allow to significantly reduce the temperature gradients (by a factor 2.5 , e.g., from $100 \mathrm{mK}$ to $41 \mathrm{mK}$ at $T_{\mathrm{amb}}=0{ }^{\circ} \mathrm{C}$ ) inside the silicon surrounding the Cs-vapour and that it is preferable to add coatings even onto the cell surfaces. In addition, it can be noted that convection of the Cs-vapour is expected to average the temperature distribution inside the vapour. However, the mean temperatures are still rather sensitive to the ambient temperature although, once again, the metallic coatings decrease this dependence by a factor 2.6 (e.g., from a difference of $2.61 \mathrm{~K}$ to $1 \mathrm{~K}$ when the ambient temperature varies from $0^{\circ} \mathrm{C}$ to $\left.55^{\circ} \mathrm{C}\right)$.

Consequently, we propose in the following a dynamic adjustment of $T_{\text {set }}$ to compensate this dependence as it will be shown in the Section 4.

Similar simulations were also performed with FloTHERM computational fluid dynamics software, this time considering the overall device. Boundary conditions were the following ones: $1 /$ The whole structure lies in vacuum, and a fluid (thermal conductivity $5 \times 10^{-4} \mathrm{~W} / \mathrm{mK}$ ) is contained inside the cell (imitating the
Cs-vapour), 2/Heat transfer effects such as radiation (each surface having its own emissivity) and conduction, are taken into account. It has to be noted that results are given for the steady-state regime. Since FloTHERM considers only fluids, vacuum is simulated by setting a very low thermal conductivity for the surrounding fluid and high thermal resistances at the solid-fluid-surfaces, so that heat conduction between solids and fluid does not occur. There is however one exception: inner walls of the Cs-cavity are not resistive for heat conduction.

FloTHERM simulation results are in very good agreement with the ones resulting from the simplified approach and assumptions used with Intellisuite software. As an illustration, Fig. 8 shows the temperature distribution inside the device core, i.e. the Cs-cell for the second case considered in Intellisuite, i.e. coatings added only onto the LTCC part. It can be noted that the temperature of the Csvapour is, as mentioned previously, homogenised (equal to $80.03^{\circ} \mathrm{C}$ at different places of the cavity). Thus, a gradient as high as $0.6 \mathrm{~K}$ inside the solid structure (glass and silicon) is not expected to be critical.

\subsection{Preliminary experiments}

Preliminary experiments have been performed with a prototype of the Cell-submount, in order to validate the heating resistors and sensor for temperature control of the cell. The aim is to estimate the required power and the resulting temperatures. This prototype is made of a LTCC suspension structure where heating resistors and temperature sensor are embedded. The structure hangs a Cs-cell and the whole prototype is placed in a vacuum chamber ( $1 \mathrm{~Pa}$ ) at $25^{\circ} \mathrm{C}$. It can be mentioned that the LTCC as well as the Cs-cell are not coated with metal. Since the chamber is large compared to the prototype, it can be consider that the environment is equivalent to a black-body (emissivity close to 1 ). This situation is actually not optimal in terms of power consumption and thermal control. Thus, it corresponds more to the case without coating considered in the previous simulations. Some records are given in Fig. 9.

Different values of the heat power have been applied to the heaters and the temperature has been recorded accordingly. From these different steps, a prototype thermal resistance (see Eq. (1)) around $830 \mathrm{KW}^{-1}$ can be deduced. Then, $66 \mathrm{~mW}$ and $96 \mathrm{~mW}$ would be required to reach $80^{\circ} \mathrm{C}$ at $T_{\mathrm{amb}}=25^{\circ} \mathrm{C}$ and $T_{\mathrm{amb}}=0^{\circ} \mathrm{C}$, respectively. With metal coatings, as shown by the previous simulations and a better vacuum, such power consumption should be significantly reduced.

\section{Dynamic adjustment of the set temperature}

Simulation results described in Section 3.3 have shown that, in addition to vacuum packaging and bridges suspensions, metallic coatings improve significantly the temperature control by reducing the gradients inside the core, i.e. the Cs-cell, as well as the difference between the mean cell temperature and the set temperature. However, as it was mentioned previously. The temperature shift between the sensor and the silicon part of the cell still strongly depends on the outer temperature so that over $1^{\circ} \mathrm{C}$ shifts can be 
a

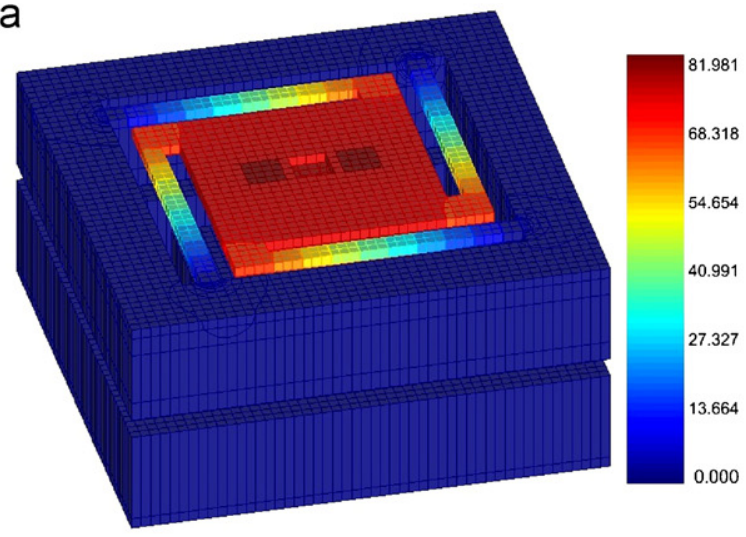

C

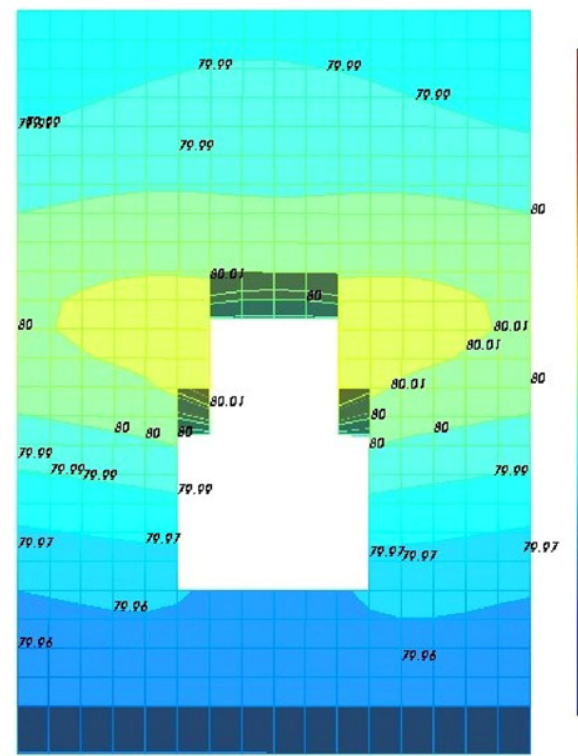

b

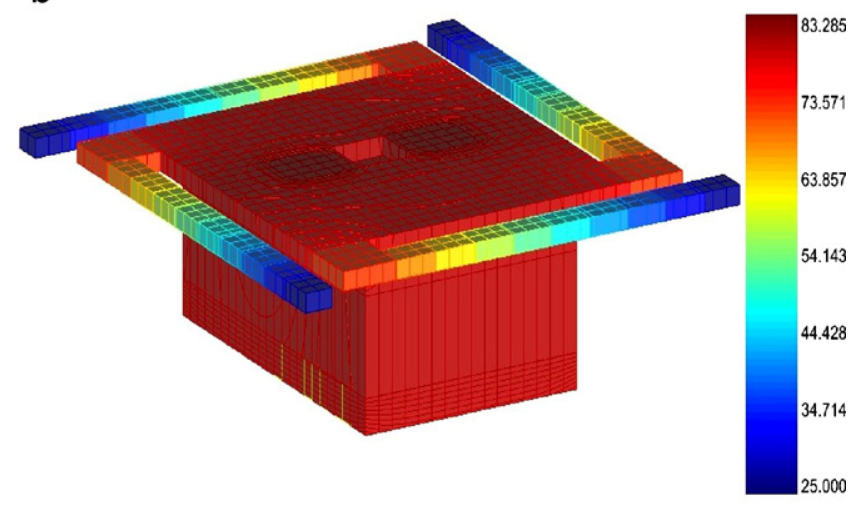

d

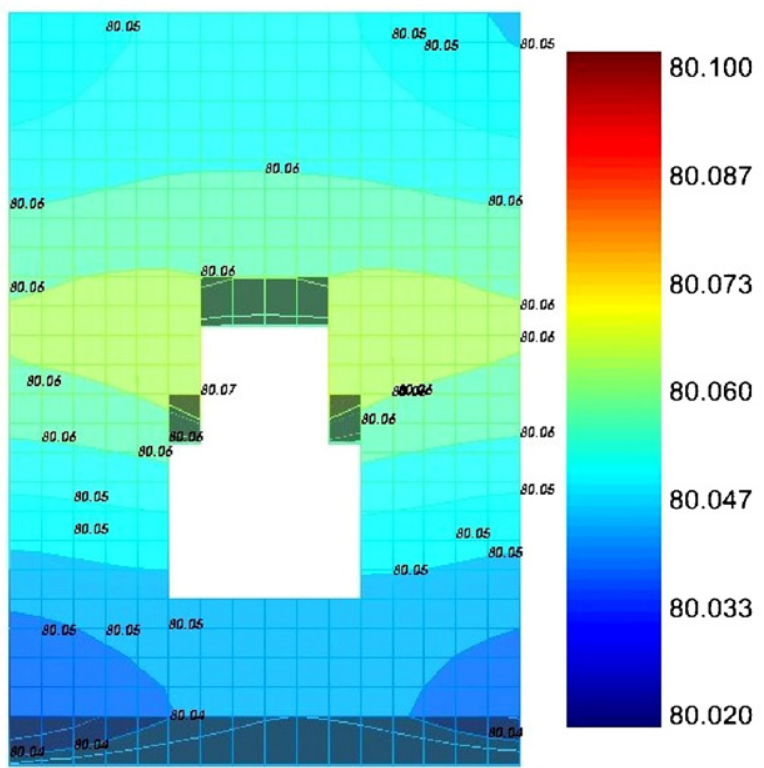

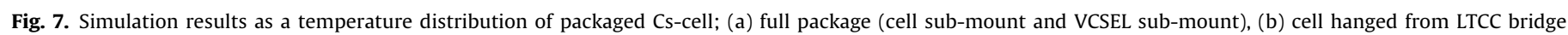

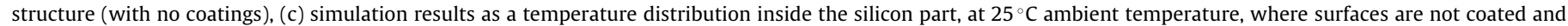

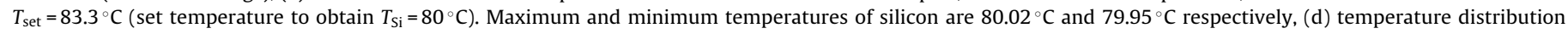

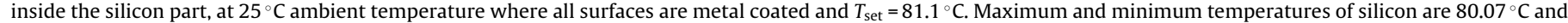
$80.04^{\circ} \mathrm{C}$ respectively.
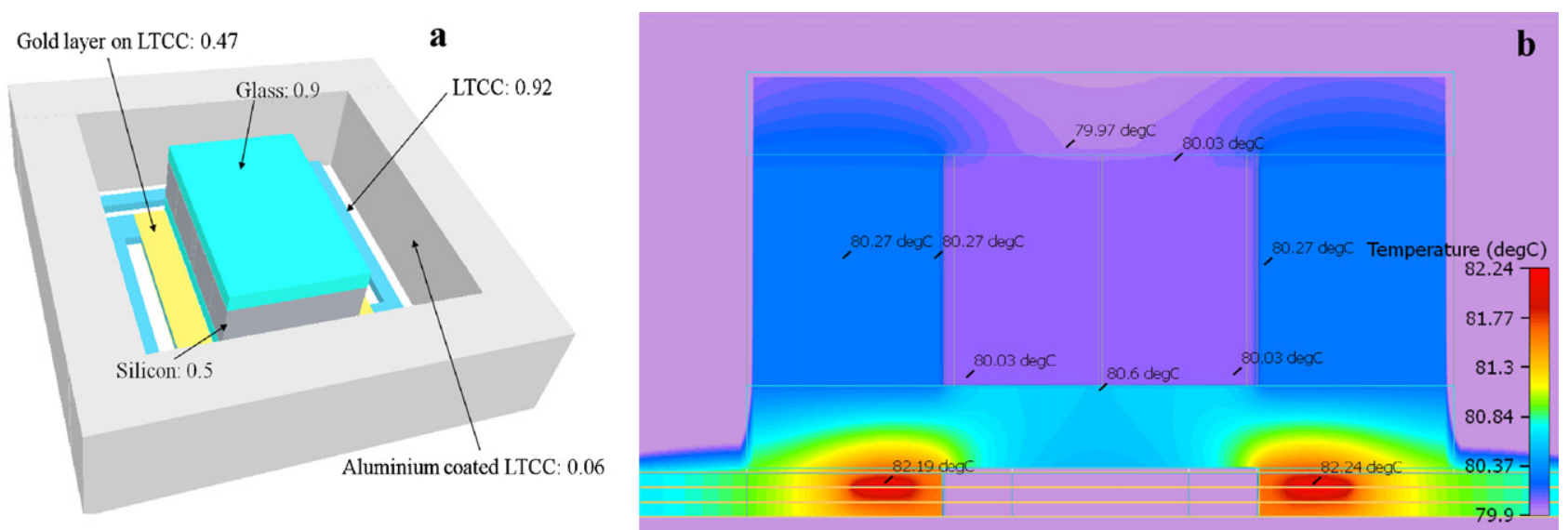

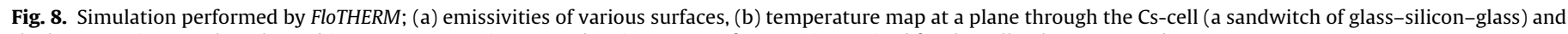
the heater resistors, when the ambiant temperature is $25^{\circ} \mathrm{C}$. A heating power of $50 \mathrm{~mW}$ is required for the cell-submount steady state. 

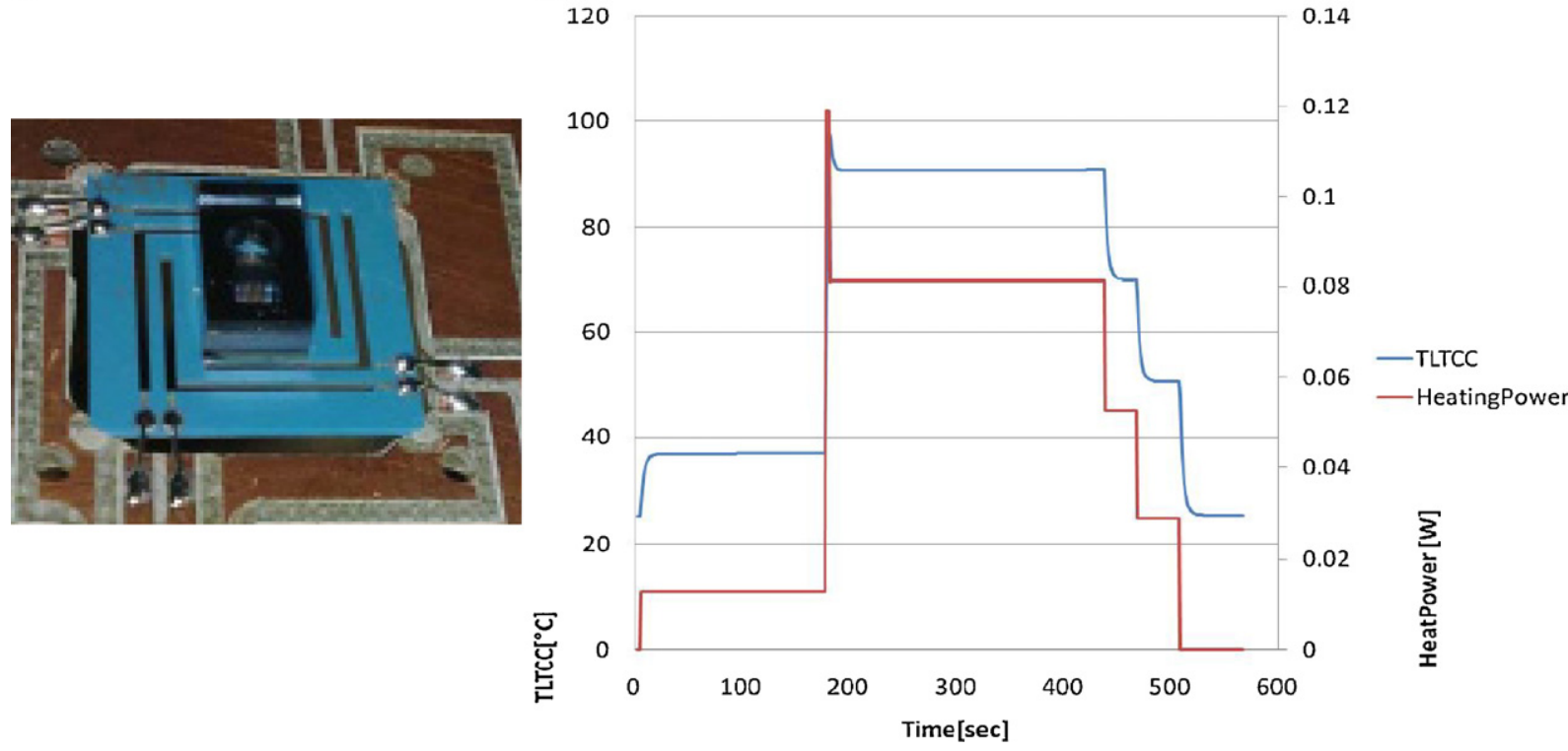

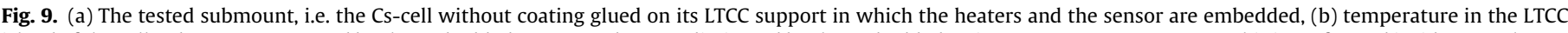

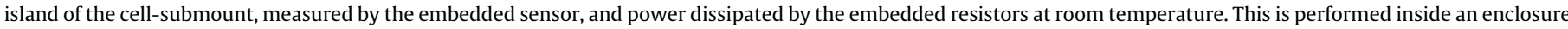
at $1 \mathrm{~Pa}\left(10^{-5} \mathrm{Bar}\right)$.

observed when the ambient temperature varies from $0{ }^{\circ} \mathrm{C}$ to $55^{\circ} \mathrm{C}$. This is a consequence of the cell architecture and the way it is glued on its LTCC stand. Because of the bad thermal conductivity of glass, the thermal conductance between the best temperature-controlled part, i.e. the sensor, and the interesting part, the silicon slice, is still quite low. The remaining parasitic flux flowing from the heaters close to the sensor through the sandwich of glass-silicon-glass generates this undesirable temperature gradient, and as a consequence, leads to a strong link between the temperature of the sensitive part and the ambient temperature. Thus, it would be preferable to adjust the set temperature as a function of the ambient temperature to compensate the resulting gradient as it is shown in Table 2.

In such case, although the temperature gradient into the silicon still depends on the ambient temperature, the mean temperature remains equal to $80^{\circ} \mathrm{C}$. The relationship between the silicon temperature and the ambient temperature can actually be electronically compensated [32]. This compensation consists in adjusting the set temperature as a function of the ambient temperature (measured by a second sensor at $T_{\mathrm{amb}}$, for example or by monitoring the consumed power) instead of maintaining it constant (Fig. 10). This
Table 2

Mean temperatures and temperature gradients in the silicon part as a function of the ambient temperature when the set temperature is adjusted in order to get $T_{\mathrm{Si}} \approx 80^{\circ} \mathrm{C}$ (values obtained from Intellisuite).

\begin{tabular}{rlll}
\hline$T_{\text {amb }}\left({ }^{\circ} \mathrm{C}\right)$ & Mean $T_{\mathrm{Si}}\left({ }^{\circ} \mathrm{C}\right)$ & $T_{\text {set }}\left({ }^{\circ} \mathrm{C}\right)$ & $\begin{array}{l}\text { Temperature } \\
\text { gradient in silicon } \\
\left({ }^{\circ} \mathrm{C}\right)\end{array}$ \\
\hline 0 & 80 & 81.55 & 0.042 \\
25 & & 81.15 & 0.030 \\
55 & & 80.55 & 0.013 \\
\hline
\end{tabular}

correction function is obviously related to the ratio of the thermal resistances between the sensor, the silicon slice at $T_{\mathrm{Si}}$ and the outer enclosure at $T_{\mathrm{amb}}$. By means of this electronic correction, the resulting temperature change in the silicon cell-core versus the ambient temperature change can be reduced by an expected factor of 10, typically, without any substantial increase of the power consumption. Consequently, such adjustment should allow to reach a temperature control of the solid parts of the cell around $100 \mathrm{mK}$ over the range $\left[0^{\circ} \mathrm{C}, 55^{\circ} \mathrm{C}\right]$, with gradients smaller than $50 \mathrm{mK}$. a

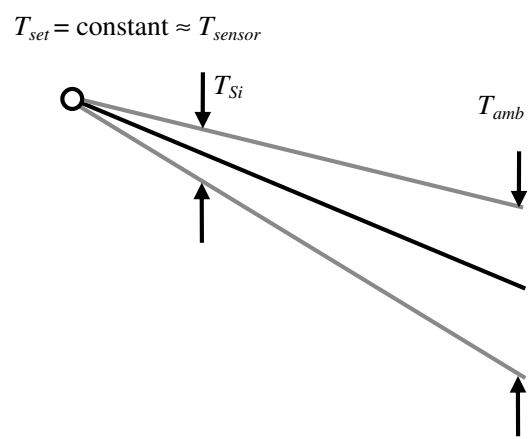

b

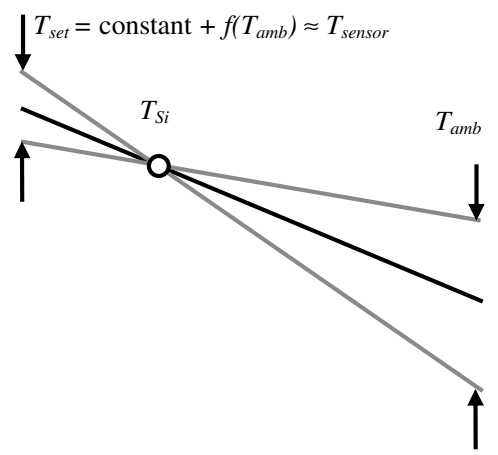

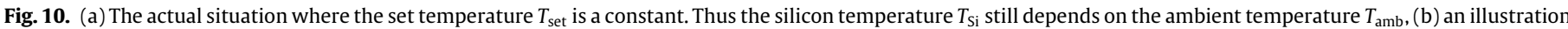
of the compensated set temperature varying according to the ambient temperature change: in such a way, the change of $T_{\mathrm{Si}}$ can be strongly reduced (ideally zero). 


\section{Conclusions}

A study of the thermal behaviour of Cs-vapour cell packaged in a Low Temperature Co-fired Ceramics (LTCC) structure for chip-scale atomic clock application has been presented. Different contributions to the thermal behaviour, such as bulk conduction, gaseous conduction and convection, and radiation, have been investigated by analytical modelling or finite element based softwares and several solutions have been proposed in order to keep the cell temperature constant during ambient temperature variations. Thanks to LTCC suspensions made of bridges, vacuum environment, and metallic coatings, it has been shown that reasonable power consumption, in the range of several tens of milliwatts, can be achieved for thermal control of the Cs-cell at an operating temperature of $80^{\circ} \mathrm{C}$. In addition, thermal gradients inside the cell have been studied and it was shown that they can be limited to few millikelvins with appropriate coatings limiting radiations. Dependence of these gradients to the ambient temperature variations can moreover be significantly reduced by a dynamic adjustment of the set temperature.

\section{Acknowledgements}

This work is supported by a collaborative project MAC-TFC of the European Commission (FP 7, ICT program, grant no. 224132). The authors thank Dr. V. Giordano for his help and valuable suggestions.

\section{References}

[1] J. Kitching, S. Knappe, L. Hollberg, Miniature vapor-cell atomic-frequency references, Appl. Phys. Lett. 81 (2002) 553-555.

[2] www.mac-tfc.eu.

[3] J. Vanier, C. Audoin, The Quantum Physics of Atomic Frequency Standards, vols. I and II, Adam Hilger, Bristol, 1989.

[4] A. Douahi, L. Nieradko, J.C. Beugnot, J. Dziuban, H. Maillote, S. Guerandel, M. Moraja, C. Gorecki, V. Giordano, Vapour microcell for chip scale atomic frequency standard, Electron. Lett. 43 (5) (2007) 279-280.

[5] L. Nieradko, C. Gorecki, A. Douahi, V. Giordano, J.C. Beugnot, J. Dziuban, M. Moraja, New approach of fabrication and dispensing of micromachined cesium vapor cell, J. Micro-Nanolithogr. MEMS MOEMS 7 (2008) 033013.

[6] M. Hasegawa, R.K. Chutani, C. Gorecki, R. Boudot, P. Dziuban, V. Giordano, S Clatot, L. Mauri, Microfabrication of cesium vapor cells with buffer gas for MEMS atomic clocks, Sens. Actuators A: Phys. 167 (2011) 594-601.

[7] P. Karioja, K. Keränen, M. Karppinen, K. Kautio, V. Heikkinen, M. Lahti, J. Ollila, J.T. Mäkinen, K. Kataja, J. Tuominen, T. Jaakola, S.H. Park, P. Korhonen, T. Alajoki, A. Tanskanen, J. Lenkkeri, J. Heilala, LTCC toolbox for photonics integration, in: Proc. of IMAPS/ACerS, 2nd Int. Conf. on Ceramic Interconnect and Ceramic Microsystems Technologies (CICMT), Denver, 2006.

[8] S. Knappe, J. Kitching, L. Hollberg, Temperature dependence of coherent population trapping resonances, Appl. Phys. B Lasers Opt. 74 (2002) 217-222.

[9] E.C. Beaty, P.L. Bender, Narrow hyperfine absorption lines of $\mathrm{Cs}^{133}$ in various buffer gases, Phys. Rev. 112 (1958) 450-451.

[10] N. Allard, J. Kielkopf, The effect of neutral non-resonant collisions on atomic spectral-lines, Rev. Mod. Phys. 54 (1982) 1103-1182.

[11] D. Miletic, P. Dziuban, R. Boudot, M. Hasegawa, R.K. Chutani, G. Mileti, V. Giordano, C. Gorecki, Quadratic dependence on temperature of the Cs 0-0 hyperfine resonance frequency in a single Ne buffer gas microfabricated vapor cell, Electron. Lett. 46 (2010) 1069-1071.

[12] J. Kitching, S. Knappe, P. Schwindt, V. Shah, L. Hollberg, L-A. Liew, J. Moreland, Power dissipation in a vertically integrated chip-scale atomic clock, in: Proceedings of the IEEE International Ultrasonics, Ferroelectrics and Frequency Control Conference, 2004, pp. 781-784.

[13] S. Knappe, in: Y. Gianchandani, O. Tabata, H. Zappe (Eds.), MEMS Atomic Clocks in Comprehensive Microsystems, vol. 3, Elsevier, Oxford, UK, 2007, pp. 571-612.

[14] M. Mescher, R. Lutwak, M. Varghese, An ultra-low-power physics package for a chip-scale atomic clock, in: Proceedings of Transducers'05, 1, 2005, pp. 311-316.

[15] H.-S. Kim, H.-H. Liao, H.O. Song, T.W. Kenny, Variable thermal resistors (VTR) for thermal management of Chip Scale Atomic Clocks (CSAC), in: Proc. IEEE Int Conf. MEMS, 2008, pp. 852-855.

[16] A.D. Laws, Y.J. Chang, V.M. Bright, Y.C. Lee, Thermal conduction switch for thermal management of chip scale atomic clocks, J. Electron. Packag. 130 (2008) 021011.1-021011.6

[17] A.D. Laws, R. Borwick, P. Stupar, J. DeNatale, Y.C. Lee, Thermal and structural analysis of a suspended physics package for a chip-scale atomic clock, J. Electron. Packag. 131 (2009), 041005.1-041005.9.
[18] A. Al-Samaneh, S. Renz, A. Strodl, W. Schwarz, D. Wahl, R. Michalzik, Polarization-stable single-mode VCSELs for Cs-based MEMS atomic clock applications, SPIE Int. Soc Opt. Eng. 7720 (2010) 772006.

[19] G.A. Bird, Molecular Gas Dynamics and the Direct Simulation of Gas Flows, Clarendon Press, Oxford, 1994.

[20] G.S. Springer, Heat transfer in rarefied gases, in: T.F. Irvine, J.P. Hartnett (Eds.), Advances in Heat Transfer, Academic Press, New York, 1971, pp. $163-218$

[21] E.H. Kennard, Kinetic Theory of Gases, McGraw-Hill, New York, 1938

[22] F.S. Sherman, A Survey of Experimental Results and Methods for the Transition Regime of Rarefied Gas Dynamics, in: J.A. Lauermann (Ed.), Rarefied Gas Dynamics, II, Academic, New York, 1963, pp. 228-260.

[23] J. Taine, J.-P. Petit, Cours et données de base Transferts thermiques. Mécanique des fluides anisothermes, second ed., Dunod, Paris, 1995.

[24] N.M. Ravindra, K. Ravindra, S. Mahendra, B. Sopori, A.T. Fiory, Modeling and simulation of emissivity of silicon-related materials and structures, J. Electron. Mater. 32 (2003) 1052-1058.

[25] Y.S. Touloukian, D.P. Dewitt, Thermal radiative properties Non Metallic Solids, vol. 8, IFI Plenum, New York, 1970.

[26] J.H. Lienhard IV, J.H. Lienhard V, A Heat Transfer Textbook, third ed., Phlogiston Press, Cambridge, 2008

[27] Data from VTT technical research center of Finland.

[28] Y.S. Touloukian, D.P. Dewitt, Thermal radiative properties Coatings, vol. 9, IFI Plenum, New York, 1970.

[29] D.W. Youngner, L.M. Lust, D.R. Carlson, S.T. Lu, L.J. Forner, H.M. Chanhvongsak, T.D. Stark, A manufacturable chip-scale atomic clock, in: Proc. 14th Intl. Conf. Solid-State Sensors, Actuators and Microsystems (Transducers'07), Lyon, France, 2007, pp. 39-44.

[30] http://www.engr.uky.edu/rtl/Catalog/.

[31] J.P. Holman, Heat Transfer, 6th ed., McGraw-Hill, Inc., New York, 1986.

[32] S. Galliou, M. Mourey, Temperature processing of an ultra stable quartz oscillator, IEEE Trans. Ultrason. Ferroelectr. Freq. Control 48 (2001) 1539-1546. 